\title{
Bringing Culture into a Foreign Language Class: A Way to Enhance Intercultural Education in Multi- ethnic Groups
}

\author{
Mariya Burlakova ${ }^{1}$ Aleksei Mikhailov ${ }^{1, *}$ Tatiana Burlakova ${ }^{1}$ \\ ${ }^{1}$ Ivanovo State University (Shuya Branch), Ivanovo, Russia \\ "Corresponding author. Email: rektorat@mail.ru
}

\begin{abstract}
Cultural diversity is a contemporary reality. The present-date Russia is a land where different cultures co-exist. The Russian national culture itself is far from being homogenious, and the student society is also multicultural. At the same time, the level of cultural unawareness is quite high. Therefore, teachers at all levels are working towards implementing new approaches to education of their students so that they could develop intercultural competencies. The authors of the article describe some strategies of integrating intercultural and linguistic education in a multi-ethnic student group at a university. A foreign language course is believed to be a perfect environment for the students to learn about the cultural diversity and undergo transformative learning. In working with a multi-ethnic group, it has proved an efficient improvement to make a foreign language course both language- and human-oriented, so that, above the linguistic facts, students come to understand themselves as representatives of their culture, learn the target foreign language culture and recognize the notions representing the Russian national culture.
\end{abstract}

Keywords: Intercultural education, Foreign language class, Multi-ethnic group.

\section{INTRODUCTION}

For at least two past decades cross-cultural relations and dialogues of cultures have been a subject of concern, controversy and discussion. It is well-known that variety of cultures is the base of the human civilization. Together with that, cultural differences often become the cause of conflicts and crises, especially in the multi-ethnic communities.

All societies are nowadays more or less multiethnic. In Russia, as in most countries, whether we think in terms of the anthropological sense of culture or its aesthetic sense, cultural diversity is a fact. Not only does it provide an example of a situation where many cultures co-exist, but the Russian culture is itself plural, and allows various currents of thought and traditions to flourish. There is a wide range, on the one hand, of languages, religions, customs and ways of life, on the other hand, of literary and artistic modes of expression.

But if Russia's cultural diversity is an empirical reality, the normative attitude towards this reality varies. Any society can respond to its cultural diversity in one of two ways, each one capable of taking different forms. It might welcome and cherish it, make it central to its self-understanding, and respect the cultural demands of its constituent communities. Or it might seek to assimilate these communities into its mainstream culture either wholly or substantially.

In Russia, the State officially recognizes cultural diversity. The society is multicultural. But, in fact, the level of cultural unawareness and, more importantly, of intolerance is dangerously high. It is therefore high time that we thought of a new approach towards education of the people so that they could learn to accept the ones having a different cultural background. 


\section{THEORETICAL AND METHODOLOGICAL RESEARCH ON INTERCULTURAL EDUCATION}

Interculturalism is the challenge of the XXIst century. School is one of the privileged places where that challenge can be met, yet there is a great need for the specific means to accomplish the task.

It is a commonly accepted fact that learning a new language means both developing a language proficiency and obtaining a new mentality. Language is the principle means whereby we conduct our social lives. Thus, the quality of language teaching can help or destroy successful socialization. It has been proclaimed that language teaching has now the goal of providing crosscultural communication and mutual understanding between nations. Without a knowledgeable and culturally skilled citizenry, it seems impossible to maintain a free and democratic land.

There are various definitions of the term culture. According to one of them, it is "the set of rules of learned behaviors that a group of people shares and it defines the context in which we exist, think, feel and relate to others" [1]. Thus, key to understanding and acquiring the rules of culture is the ability to identify the orientations and the values underlying them, the interpretation of the beliefs stemming from the values and the expression of these values through the oral and written forms of the language [2].

Pedagogics studies various aspects of culture teaching and learning. But the latest vision of the multicultural education in the classroom concerns addressing students' real-life experience of diversity over the textbook version, and modeling lessons to suit the needs of a particular student group [3]. While book knowledge about diverse cultural groups is still considered meaningful when designing lesson plans and educational materials, one of the most important reasons for truly learning about other cultural groups is so that the interpersonal attitudes and behaviors of diverse students can be effectively interpreted in terms of the culture that they're entrenched in. Besides, teachers are supposed to create assignments that celebrate multiculturalism [3].

Another topical trend in the pedagogics is equity in education. While some aspects of equity in education must be addressed on a broader systemic scale, there are many things that can be done at the individual classroom [4] [5].
For this research, focusing on young adult education, transformative learning theory is also fundamental. It is so important because, when it comes to teacher training, transformative learning can help an individual to be more critical, autonomous, and ultimately responsible to the learning environment and adjust their thinking based on new information [6] [7]. A particular culture ought to be viewed in the complexity of its goals, expressed in values, ideas, behaviours, that are considered desirable in the society [8].

There are scholars who argue that the features of a particular national culture of behavior and ethno-psychological characteristics have an impact on the learning style of an individual and, therefore, the teacher is expected to be able to select the appropriate teaching methods and techniques [9] [10] [11].

What is vital for maintaining effective multicultural education at the national level is developing cultural identity of the prospective teachers at teacher training universities so that they develop multicultural literacy in order to be able to work in multi-ethnic classes [12] [13].

Of course, students can learn the history of a certain nation, key attributes of the culture, stories of value-positive episodes of the culture, and the duties, obligations, rights and privileges of the culture. This is primarily an academic approach to be accomplished through lectures, reading, writing, film, and related assignments. In this case the curriculum materials needed are histories, original documents, stories, biographies. But it takes a specialized course and a great deal of time. Another point is that few people who have come to teach at the pedagogical university have enough academic time to take up such a complicated and prolonged course. That is where a traditional language course comes in handy.

There is no denying the fact that cultural peculiarities are harder to teach than the language, although the former causes a greater number of misunderstandings and, due to the power of cultural identity, mistakes concerning culture are not so easily accepted and forgiven as linguistic ones. There might be different approaches to characterizing cultures but the core categories are referred to as follows:

- Sense of Self and Space, as each culture validates self in a unique way; 
- Communication and Language, as both verbal and non-verbal communication distinguishes one group from another;

- Dress and Appearance, that is, the outward garment and adornments, or lack of them, piercing, body decorations;

- Food and Feeding Habits, as the manner in which food is prepared, served, and eaten often differs by culture;

- Time Consciousness: some cultures are exact, others are relative;

- Relationships, for cultures fix human relationships by age, degree of kindred, power;

- Values and Norms, as different priorities are attached to certain cultural behaviors;

- Beliefs and Attitudes, or greater or smaller degree of concern for the supernatural, evident in the every-day life;

- Mental Process and Learning, as some cultures emphasize one aspect of brain development over another, so there may be differences in the way people think and learn;

- Work Habits and Practices, which include attitude toward work, work habits or practices like promotions and rewards [14].

Those constituents might be of different significance in revealing various ethnic cultures, it is clear that the Turkmen are different from the Armenians and the Russians differ from either of them in temper and prevailing mood, mentality, gestures, moral and material values, habits, social norms, understanding of time and space, meaningful colors, outlook, social groups and relations dominating in the culture. But in general, these categories on the whole might become a solid ground for working out a course aimed at teaching culture in a language classroom.

\section{AN EXPERIMENTAL STUDY OF THE STUDENTS' CULTURAL COMPETENCIES}

The authors have conducted some research at the School of Linguistics of the teacher training university in Shuya, Russia. The eighty university students taking part in the survey come from various backgrounds: there are local students, students from other Russian regions, overseas students from Turkmenistan, Uzbekistan, Tajikistan, Afganistan. All of them major in English and minor either in French or in German. It is important to mention that all the students admit that the quality of their culture and ethnic knowledge has a major impact on the language learning process.

The results of the survey are as follows. "Figure $1 "$ shows the ratio of the positive and negative answers to the question "Do the teachers use culturally important information in the language classes?"

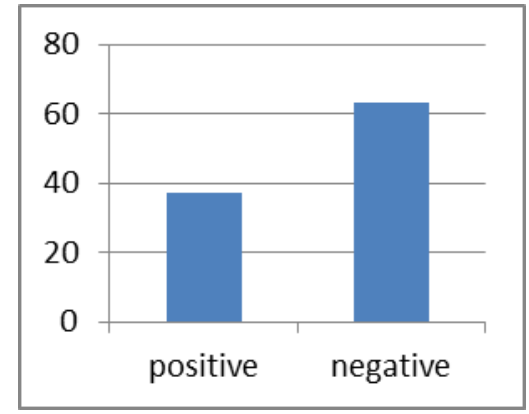

Figure 1 The ratio of the positive and negative answers to the question about the teachers using culturally important information in the language classes.

$37 \%$ of the students believe that their teachers are concerned about the cultural aspects of their language classes, while $63 \%$ think that the teachers follow the prescribed language-centered syllabus without paying much attention to the matters of cultural significance.

"Figure 2" displays the specific aspects of the cultural information the students learn in their language classes, as it follows from the survey.

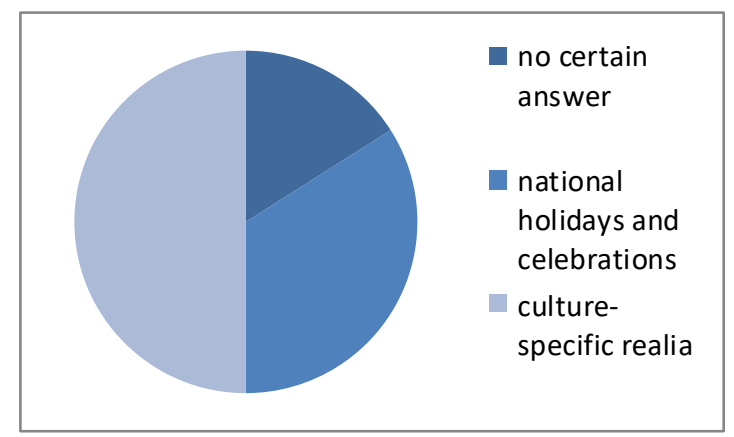

Figure 2 The culture-specific information the students think they learn in the language class.

The $16 \%$ of the students were not able to specify what culture information they got to learn in their foreign language class. 34\% replied that they studied national holidays and celebrations (e.g. Christmas or Valentine's Day while doing their English language course). 50\% answered that they 
studied some culture specific realia, i.e. the words that cannot be translated, because there is no corresponding referent in their own culture (e.g. kilt as an item of clothing).

At the same time, the survey included the questions to assess what the students' true cultural competencies were.

A student was considered to have the Advanced Level of the cultural competencies (Level 1) if they had over 80 per cent of the correct answers to the questions about:

- ethnographical facts about the UK (the most important historical events, especially of the XX century, famous people, religions, folklore, arts and crafts);

- culture-specific body language;

- moral s and ethics of the nation.

A student was considered to have the Upper Intermediate Level of the cultural competencies (Level 2) if they had between 65 and 80 per cent of the correct answers to the questions. The Intermediate Level of the cultural competencies (Level 3) was rated between 50 and 65 per cent of the correct answers. A student was considered to have the Low Level of the cultural competencies (Level 4) if they had score below 50.

It was found out that only $5 \%$ of the students had the Advanced cultural competency level (Level 1). $60 \%$ of the students, which is a majority, were rated at Level 3, or Intermediate Level, while 20\% were rated at Level 2. 15\% rated at the Low Level (See "Figure 3").

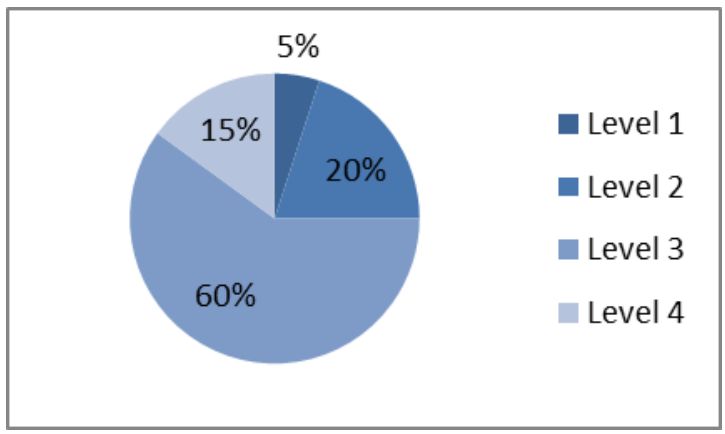

Figure 3. The levels of the students' cultural competencies.

This outcome showed that a lot of students had difficulty developing their cultural competencies, although their language proficiency was quite satisfactory.

\section{THE AUTHORS' METHODS OF BRINGING CULTURE INTO LANGUAGE CLASSES}

The authors believe that cultural competencies ought to be developed through purposefully organized activities, including project activities, within the framework of the regular language classes [15]. The teachers, of course, should enlarge the information necessary for the students giving as many details as possible, as the primary level of knowledge about a culture is never enough. This means the subdivision of cultural information into functional spheres.

What we find effective is the following order of tutorials incorporating much of background knowledge of a given linguistic community:

- culture specific notions concerning human descriptions: body and character, people's psychology, racial peculiarities of a given culture, traditional " masculine" and " feminine" values, prevailing behavioural patterns and attitudes, such as aggressiveness, competition, dominance, hierarchy, etc.

- every-day routines,

- mentality: stereotypes and morals,

- relationship patterns and key social roles men and women have,

- political climate: opinions, the vision of the country's position which is typical of ordinary people.

Those culturally specific components can be taught in various types of tutorials: through the analysis of the word-list or through carefully selected texts, so that students could work together and search for the meanings of the given words, coming across some culturally important terms, pose questions, compare, discuss, and that brings up self-awareness and awareness of others.

While discussing those topics, it is necessary that the teacher should pay attention to the vocabulary that often carries a heavy weight of accumulated baggage of culture-specific meanings. Even simple words like blue, individual, optimism can carry a wide range of connotations and associations alongside their denotations. For instance, being characterized as an adherent of materialism has a different effect on the American and Russian people. For the Russians it mostly has negative connotation, for the Americans, on the contrary, there is a tendency toward a positive 
evaluation of such characteristics. If given a short dialogue containing this word, at the first stage our students take it as an offence, on the second they are apt to take it as a compliment with the reference to American mentality, even if the teacher put it into the dialogue in the negative meaning. At the last stage the students are still treating it properly in the conversation with the Americans and stop using it in the conversation with the Russians.

The talks help the students to understand the images of the cultures. Sometimes the teacher corrects the false image or gives some details. Finally, the students share their conclusions on how much realities correspond or resemble to the Russian culture. Such tasks are rather effective for accentuating students' self-awareness.

At the advanced level the tasks are more creative, accurate, giving background knowledge of the native speakers about notions, historical and cultural allusions, which is very helpful for students. Students might be given a letter out of the word list to look through and they tell what they didn't know but what they find useful concerning the target culture. They might come up with a list of traditions and try to give the difference from the Russian culture. The teachers try to arise as many associations as possible to make the students' knowledge solid. Discussing Guy Fawkes Night, for instance, the question for students to think about: On what Russian/Armenian/Georgian/American holidays the same amount of fireworks can be set off?

For some students who have higher activity level that is associated with a commitment to get more work done, there is a task to make a glossary using the material from the offered dictionary. The glossary may contain up to thirty words describing some important issues concerning, for example, British more or less specific social realias, like contributory pension scheme, litterbug, etc. Students are asked to give their own definitions to those phenomena, as if they try to describe them to those who know nothing in this particular sphere of British life. The same task is given to three or four students. Finally, the rest of the group share what they have gained.

The ultimate goal is students' going through the three phases of changing the relationship between the two images of home and target culture. We label the phases of relationship development as dependence, independence and interdependence. At the beginning of the course Russian students tend to be very dependent on the home culture image, it is followed by a period of total independence from the home culture with the accent on a foreign culture. The mature phase of the relationship is described as interdependence, where the students simultaneously use the images of the two cultures without mingling them and are able to value both dimensions.

The necessary part of the curriculum is concentrating on deleting prejudiced, inadequate information about a culture, the so-called stereotypes. Here we are also trying to apply strategies for low and very low openness, which is frequent, actually, namely:

- coming from the students' existing interests. If they resist learning new facts in a new context, we apply a familiar context. E.g., if they like watching TV, then we use TV examples to explain some political clichés;

- if some students lack curiosity and inquisitiveness, especially about unfamiliar things, we pose questions and options rather than expect them to come up with their own lists of question;

- planning explaining unconventional beliefs or practices later in the course, when the students open up to learning from others without judgment.

We try to encourage students to realize that the process of teaching culture and languages cannot be understood as only giving facts, because it always has the shade of evaluation, acceptance or neglecting, and the information given is supposed to be actively used in real communication in order to form a positive attitude to the culture under study. So, there are reflective talks in the curriculum, and the dictionary is to continually help students reflect on how different their culture is from the other, what common notions they have, what they can do to make the discrepancies invisible for the partners in communication.

Learners become active cultural beings as they are involved in interaction with individual cases finding their own way of being in the world, while the teacher acts as a 'detached-concerned' middleman, or an intercultural broker who interprets a multiplicity of realities to students who in turn arrive at their own understandings of them.

Tradition and historical transmission is of importance in the whole process. The inclusion of the cultural heritage of the source culture and the target culture in the model in particular marks a break with cultural teaching syllabus design of the past and present. Culture is presented as dynamic; 
the selected elements of the past and their relevance to the present and the future can be perceived as an extension of cultural goals leading not only to intercultural competence, but intercultural literacy in language learners.

\section{GENERAL CONCLUSION}

Multicultural education embraces a lot of things: traditional learning, pedagogy of equity, strengthening the educational culture of the school, the ability to use the cultural peculiarities of students to their advantages rather than to their disadvantages.

The conducted study showed that a majority of the students at the School of Linguistics of the teacher training university in Shuya, Russia had intermediate level of cultural competencies, although they belonged to different ethnic groups. It means that studying together is not enough for them to become more culturally literate. A foreign language teacher can be the facilitator who will enhance the learning about the culture of the language, and through it, the students will develop the necessary competencies so they can become intercultural mediators in a multi-ethnic nation.

\section{AUTHORS' CONTRIBUTIONS}

The article has been written by a team of authors, all authors have taken equal part in the theoretical analysis of the problem and in carrying out the research. M.V. Burlakova analysed and generalized ideas of the Russian and foreign authors on the problem of the research and wrote the original manuscript. A.A. Mikhailov conducted the survey among the students and summarized the data. T.V. Burlakova made an analysis of the survey results and contributed to revising and editing the paper.

\section{REFERENCES}

[1] A. Parsons, Perfect English and Poor Communication. In: The Polyphony of Education and English Studies in the Multicultural World, Abstracts for the First International Conference of the Association of EL Teachers, Moscow, 2003, pp. 31-32.

[2] J.A. Banks, Ch. A. McGee Banks, Multicultural Education. Issues and Perspectives, John Wiley \& Sons, Indianapolis, IN, 2020.
[3] M. Lynch, Six Ways to Implement a Real Multicultural Education in the Classroom. DOI: https://www.theedadvocate.org/6-waysto-implement-a-real-multicultural-educationin-the-classroom/

[4] Equity in Education: What it Is and Why it Matters. DOI: https://www.thinkingmaps.com/

[5] Ch.E. Sleeter, M. Zavala, Transformative Ethnic Studies in Schools: Curriculum, Pedagogy, and Research (Multicultural Education Series), Teachers College Press, New York and London, 2020.

[6] What is the transformative learning theory? DOI: https://www.wgu.edu/blog/whattransformative-learningtheory2007.html\#close

[7] T. Stewart, H. Seauve, Transformative Learning and Teaching for Educational Equity and Intercultural Competence. In: Science, Education and Culture, Proceedings of the XI International Conference on Education, Ivanovo State University, Shuya, 2021, pp. 74-76.

[8] Yu. Pai, S.A. Adler, L.K. Shadiow, Cultural Foundations of Education. 4th Edition, Pearson, 2006.

[9] T.V. Burlakova, M.V. Burlakova, On the Significance of the Individualised Approach in Training Prospective English Language Teachers (in the Conversational Practice Classes). In: In the World of Scientific Discoveries, Krasnoyarsk, № 7 (43), 2013, pp. 157-168.

[10] V. Yu. Khotinetz, Ethnical Identity and Tolerance, 2nd edition, Moscow, 2020.

[11] C. Kramsch, Language and Culture, Oxford, 2000.

[12] A.N. Dzhurinsky, Polycultural Education in a Multicultural Society, Moscow, 2020.

[13] A. Barro, M. Byram, H. Grimm, C. Morgan, \& C. Roberts, Cultural Studies for Advanced Language Learners. In: D. Graddol, L. Thompson \& M. Byram, Language and Culture, Clevedon, 1993, pp. 55-70.

[14] P.R. Harris, R.T. Moran, Managing Cultural Differences, Gult Publishing Company, Nouston, London, 1993, pp. 206-210.

[15] O. Karpova, M. Burlakova, A Course on Intercultural Education: In Search of a Model. In: Proceedings of UNESCO Conference on Intercultural Education, 15-18 June, 2003, Jyväskylä, Finland. On CD-ROM. 